\title{
STALKING AMONG UNIVERSITY STUDENTS: PREVALENCE, VICTIMIZATION AND CONSEQUENCES
}

\author{
Shahla Tabassum, Mahnoor Malik, Khedija Suhail \\ Department of Gender Studies \\ Fatima Jinnah Women University, Rawalpindi \\ shahlatabassum@fjwu.edu.pk
}

\begin{abstract}
This study investigates stalking behavior campaigns between male and female university undergraduate students of Rawalpindi/Islamabad. The study also finds out the consequences of stalking behaviors of experienced male and female university students. A sample of 591 male and female undergraduate students of three public sectors universities was drawn through simple random sampling techniques. The 302 students out of 591 experienced stalking behaviors and results of victimization and its consequences were presented on a sample of 302 students, out of which 194 were female and 108 male students. The results reveal that $51 \%$ of students out of which $33 \%$ are female and $18 \%$ male experience stalking and 60\% female and $19 \%$ male students report their relationship with the offender as ex-boy/girlfriend while $16 \%$ male students mentioned their relationship with the offender as strangers. The study further shows significant results on stalking behavior campaigns as unwanted approaches like following, staring, hanging outside the department, library, cafeteria, as well as unwanted communication like phone calls, text messages, and contact through social media. Furthermore, the study shows significant results of stalking effects on female students' victims.
\end{abstract}

Keywords: Stalking, Prevalence, Victimization, Consequences, Students.

\section{INTRODUCTION}

Stalking as a persistent harassment against another person was highlighted in media in late 1980s (Purcell, Pathe \& Mullen, 2002; Pathe, Mullen, \& Purcell, 2000). Initially, these were the famous personalities and celebrities who experienced repeated harassment by their fans (Purcell, Pathé, \& Mullen, 2005). With the growing incidences in public (Purcell, et al., 2002) stalking has become an emergent public, gender, and social issue (Purcell et al., 2005), with high prevalence rates (Dressing, Kuhner, \& Gass, 2005) and serious consequences on victims (Narud, Friestad, \& Dahl, 2014). Those who want to study 'stalking' may face many problems while studying this area because one cannot find the clear understanding or definition of stalking and thus researchers are unable to form and inclusive operationalization (Fox, Nobles, \& Akers, 2011).

Stalking is a complex phenomenon and a few researchers defined stalking as unwanted (Purcell, Pathe, \& Mullen, 2005; Budd, Mattinson, \& Myhill, 2000), repeated, harassing and threatening behavior (Van Der Aa, 2018; Westrup, \& Fremouw, 1998) used against a person to frighten him/her. The most common behaviors reported were where victims were forced to communicate with the stalker in some way (Budd et al., 2000) while unwanted phone calls were frequently reported by the victims (Rosenfeld \& Lewis, 2005). The number of actions that include stalking behavior is threatening or harassing a person during repeated activities like following the person, making phone calls, standing outside the victim's home leaving phone messages and gift items (Acquadro \& Varetto, 2018; Abrams \& Robinson, 2011). Tjaden and Thoennes (2000) defined stalking as a threatening behavior of an individual used repeatedly: such as following a person, hanging outside their houses, sending text messages, making phone calls, or vandalizing their property of the person while Westrup and Fremouw (1998) defined it as a set of unwelcome, repetitive, and disturbing behaviors directed towards a person who as a result experience anxiety, anger, and fear for his/her safety or the safety of others. A study conducted on the U.S. University students of 788 and almost $11 \%$ male students and 25\% female students were reported as victims of stalking (Bjerregaard, 2000). Another study conducted on healthcare professional by Bulut, Usman, and Nazir (2021) found the prevalence rate of stalking from their clients range from 6\% to 53\% depending upon the field of profession and they know each other (Dovelius, Oberg, \& Holmberg, 
2006; Dressing et al., 2005). Both men and women healthcare professionals are victims of stalking campaigns.

Studies from the past 20 years are analogous regarding the gender of victims but most of the researchers have found that majority of stalking victims were women (Dressing et al., 2005; Morville, 1993; Narud et al., 2014; Purcell et al., 2005) and men are the main offenders (Morewitz, 2003). In male to female stalking, men impose control, punish and cause fear in women. Males employ stalking on women by different techniques like giving repeated threats, physical violence and by many harassing behaviors (Morewitz, 2003). However, an investigation carried out by Walby and Allen (2004) in the U.K. found that almost 9\% of men are subject to stalking. Moreover, it was also found that the majority of the victims of stalking have the relationship with offenders as ex-partners who were abusive during the relationship.

\section{Behaviors Characterized as Stalking Campaign}

As the term stalking is a combination of behaviors that's why it becomes very hard to measure stalking as compared to many other crimes (Fox et al., 2011). Many researchers prefer not to refer to the phenomenon as 'stalking' because not always the assessed behaviors are able to meet the legal standards of stalking (Dutton \& Winsted, 2006). There exists a hypothesis regarding stalking that the term is the result of the termination of violent relationship but still the findings regarding the connection between violence and stalking are very few (O'Conner \& Rosenfeld, 2004). Fox and his colleagues (2011) have criticized many findings on stalking because according to them varying definitions of the phenomenon has led researches to use different approaches in order to measure stalking which may then cause confusion whether the researchers are measuring stalking or other phenomenon.

However, Spitzberg and Cupach (2014); and McEwan, MacKenzie, Mullen, and James (2012) theorized categories of behaviors that characterized stalking behavior into three dimensions as unwanted communication, unwanted approaches, intimidations, and harassment. The unwanted communication includes any means of contact like telephone calls, letters, e-mails, cards, and text messages, etc. while the unwanted approaches include spying, following, or lurking outside victim's house or workplace, etc. The third category intimidation and harassment mean to create fear through either threat to the victim, her/his family, or seeking information about them from a third party, deformation, etc.

\section{Effects of the Stalking Campaign}

Korkodeilou (2016) found that the threatening nature of stalking often worsens quality of life for the victims as they may face mental/psychological health problems resulting in alienation, social isolation, and low self-esteem. Victims also faced difficulties in building their relationships with family, friends, partners, and children due to stalking campaign behavior. A study conducted with male and female healthcare professionals by Aquadro and Varetto (2018) reported that they experience stalking in a romantic relationship and their motive was to disrupt the intimate relationship. Female participants indicated verbal, physical, and sexual abuse while males indicated verbal abuse only. Another study conducted by Aquadro, Corona, Varetto, and Tirassa (2020) investigated police-reported cases of stalking campaigns by men and women in three cities of Italy, where $32 \%$ men and $68 \%$ of women filed these stalking cases. The findings revealed that women reported earlier to the police as compared to men. Men reported late because of the fear of the consequences and men victims were not effective in using coping strategies as compared to women.

In Pakistan, for the last two decades, studies were carried out on sexual harassment to see the prevalence, causes, and effects on victims but stalking was not studied to see its causes and consequences on victims. This study was an attempt to see gender differences on stalking behaviors and consequences on survivors of universities of Rawalpindi/Islamabad.

\section{Research Question}

To what extent, university students have experienced stalking behaviors and what were the consequences of stalking on victims? Is there any difference of stalking behavior among the students based on the gender? 


\section{METHODOLOGY}

Participants: The data was collected from undergraduate students of three public sector co-education universities of the twin cities of Rawalpindi/Islamabad. There were approximately 3000 undergraduate students in all three universities and this figure was calculated from the statistical reports of the last three years of enrolled students on the websites. The sample size was calculated $20 \%$ from the target population and it was 600 male and female students. Almost 700 students were requested to participate in the study. The participants, who responded yes on experienced stalking, were given an additional page of questions to determine the effects of stalking on victims. Only 591 students responded back and out of which 292 were female and 299 male students. The participants who experienced stalking were 302 out of which 194 were female and 108 male students. The results presented here are only of 302 students who experienced stalking, but they were approached in a systematic way.

\section{Figure 1: Flow of selection of participant}

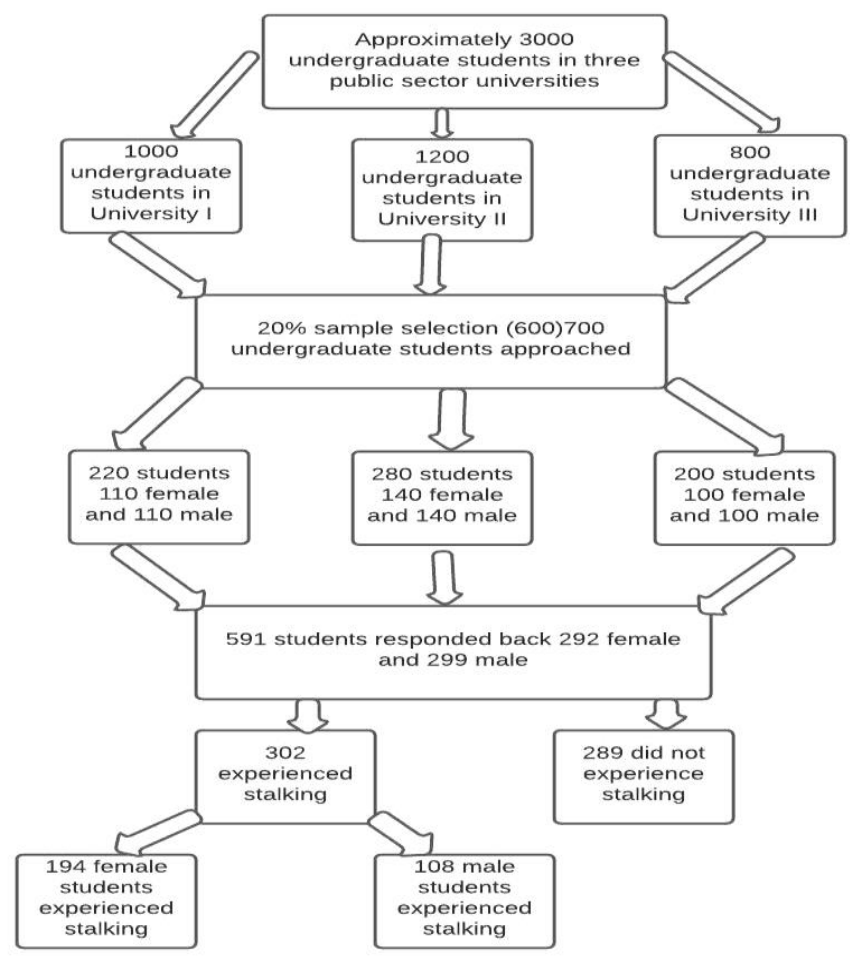

\section{Measure}

Stalking was measured through a self-structured questionnaire and the items were generated through literature and adopted in our cultural context in three phases. Pre-pilot phase, pilot study, and actual study.

Phase I: The pre-pilot phase also called the item generated phase and initially 20 items of the stalking campaign were gathered, and 14 items consisted of stalking behavior and one item was on experienced stalking and five items were effects of stalking on victims.

Phase II: In the pilot phase, the questionnaire was pre-tested, and this small study was conducted in a private co-education university of Rawalpindi. The forty male and female students participated in it. As a result of this pilot study, some items modified, reduced and reliability was measured statistically.

Table No. 1: Reliability of the tool $(n=40)$

\begin{tabular}{ccc}
\multicolumn{1}{c}{ Stalking } & No of items & Cronbach's Alpha \\
\hline Stalking Behaviors & 14 & .822 \\
Effects of stalking & 05 & .872 \\
\hline
\end{tabular}


Table 1 reveals the reliability of the questionnaire that comprises of stalking behaviors and effects of stalking on victims. The total items of stalking behaviors were 14 and the statistical calculated reliability was .822 . The total items of effects of stalking were 05 and the reliability of the items was .872 which shows that items are good to measure stalking behaviors and effects of stalking on victims.

\section{Procedures}

One of the authors personally collected data with the help of a five members' team of data collectors who were trained by the principal researcher and all the six members visited the universities and distributed the questionnaires after confirming their undergraduate studentship. The team spent six days in the universities from morning to evening to complete the data collection process. The team approached the students at the main library gates and outside cafeterias. After screening questions, they distributed the second page that reported the experience of stalking to collect the data on the effect of stalking on victims. The second author herself entered data on SPSS and calculated descriptive measures (frequencies and percentages) for all variables and $\chi^{2}$ test was applied to measure the differences between the sexes.

\section{Ethical Considerations}

The letter of informed consent was given to each participant attached with each questionnaire to get permission from them so the participants can fill the questionnaire voluntarily. It was also mentioned in the consent letter that the information that has been taken from them will be kept confidential. However, the data gathered of the students for calculating sample size was public, and there was no need to get permission from the universities.

\section{RESULTS}

Table No. 2 Characteristics of the Participants

\begin{tabular}{llll}
\hline Year of undergraduate & & Male & Female \\
& $1^{\text {st }}$ & $46(8 \%)$ & $40(7 \%)$ \\
& $2^{\text {nd }}$ & $112(19 \%)$ & $109(18 \%)$ \\
& $3^{\text {rd }}$ & $54(9 \%)$ & $59(10 \%)$ \\
Experience stalking campaign & $4^{\text {th }}$ & $87(15 \%)$ & $84(14 \%)$ \\
& & & \\
Relationship with the offender & Yes & $108(18 \%)$ & $194(33 \%)$ \\
& No & $98(17 \%)$ & $191(32 \%)$ \\
& Ex-husband/wife & 1 & 1 \\
& Ex. friends & $56(19 \%)$ & $198(60 \%)$ \\
& Acquaintance & $3(1 \%)$ & $5(2 \%)$ \\
& Stranger & $48(16 \%)$ & $6(2 \%)$ \\
\hline
\end{tabular}

Table 2 shows the results of the year of education of the participants, their experience of stalking, and their relationship with the offenders. The 15\%, 37\%, 19\%, and $29 \%$ from first, second, third-, and fourth-years male and female students participated respectively in the study. The participants who experienced stalking were 33\% female and 18\% male students and the rest $49 \%$ students did not experience stalking. The relationship with the offender was reported as the ex-friends by $60 \%$ female and $19 \%$ male students while the $16 \%$ male students reported relationships with offenders as strangers. Male students were stalked by unknown female fellows while this was not the case with female students.

Table No. 3 Behavior Characterizing Stalking Campaign

\begin{tabular}{llcccc}
$\begin{array}{l}\text { Stalking } \\
\text { behavior }\end{array}$ & Students & Male & Female & $\chi^{2}$ & p \\
\hline Follow you & Yes & $42(14 \%)$ & $111(37 \%)$ & \\
\hline
\end{tabular}




\begin{tabular}{|c|c|c|c|c|c|}
\hline & No & $66(22 \%)$ & $83(27 \%)$ & & .002 \\
\hline \multirow[t]{2}{*}{ Spy on you } & Yes & $68(23 \%)$ & $132(44 \%)$ & \multirow{2}{*}{.800} & \multirow{2}{*}{ n.s. } \\
\hline & No & $40(13 \%)$ & $62(21 \%)$ & & \\
\hline \multirow{3}{*}{$\begin{array}{l}\text { Stand out } \\
\text { house }\end{array}$} & Yes & $13(4 \%)$ & $62(20 \%)$ & \multirow{2}{*}{14.750} & \\
\hline & No & $95(31 \%)$ & $132(44 \%)$ & & .000 \\
\hline & Yes & $18(6 \%)$ & $6(2 \%)$ & & \\
\hline \multirow[t]{2}{*}{$\begin{array}{l}\text { Not Expose } \\
\text { herself/himself }\end{array}$} & No & $90(30 \%)$ & $188(62 \%)$ & (17.474) & .000 \\
\hline & Yes & $55(18 \%)$ & $176(58 \%)$ & \multirow{2}{*}{ (61.383) } & \multirow{2}{*}{.000} \\
\hline Staring & No & $53(17 \%)$ & $18(3 \%)$ & & \\
\hline \multirow{2}{*}{$\begin{array}{l}\text { Send unwanted } \\
\text { messages }\end{array}$} & Yes & $59(20 \%)$ & $89(30 \%)$ & \multirow{2}{*}{$.090(2.127)$} & n.s. \\
\hline & No & $49(16 \%)$ & $105(34 \%)$ & & \\
\hline \multirow{2}{*}{$\begin{array}{l}\text { Unwanted } \\
\text { phone calls }\end{array}$} & Yes & $84(28 \%)$ & $173(57 \%)$ & \multirow{2}{*}{ (11.107) } & \\
\hline & No & $24(8 \%)$ & $21(7 \%)$ & & .001 \\
\hline \multirow{2}{*}{$\begin{array}{l}\text { Verbally abuse } \\
\text { you }\end{array}$} & Yes & $56(19 \%)$ & $88(29 \%)$ & \multirow{2}{*}{ (1.172) } & \\
\hline & No & $52(17 \%)$ & $106(35 \%)$ & & n.s. \\
\hline \multirow{3}{*}{$\begin{array}{l}\text { Stalking } \\
\text { through social } \\
\text { networking } \\
\text { sites }\end{array}$} & Yes & $82(27 \%)$ & $175(58 \%)$ & \multirow{2}{*}{ (11.157) } & \\
\hline & No & $26(9 \%)$ & $19(6 \%)$ & & .001 \\
\hline & Yes & $25(8 \%)$ & $56(18 \%)$ & \multirow{2}{*}{ (1.156) } & \\
\hline $\begin{array}{l}\text { Threat to kill } \\
\text { you }\end{array}$ & No & $83(27 \%)$ & $138(46 \%)$ & & n.s. \\
\hline \multirow{2}{*}{$\begin{array}{l}\text { Threat to kill } \\
\text { your loved } \\
\text { ones }\end{array}$} & Yes & $41(14 \%)$ & $45(15 \%)$ & \multirow[t]{2}{*}{ (7.428) } & .005 \\
\hline & No & $67(22 \%)$ & $149(49 \%)$ & & \\
\hline \multirow{2}{*}{$\begin{array}{l}\text { Threat to kill } \\
\text { oneself }\end{array}$} & Yes & $22(7 \%)$ & $34(11 \%)$ & \multirow{2}{*}{ (1.347) } & n.s. \\
\hline & No & $86(28 \%)$ & $160(53 \%)$ & & \\
\hline \multirow[t]{2}{*}{$\begin{array}{l}\text { Damage } \\
\text { property }\end{array}$} & Yes & $52(17 \%)$ & $80(26 \%)$ & \multirow{2}{*}{$(.204)$} & n.s. \\
\hline & No & $56(19 \%)$ & $114(38 \%)$ & & \\
\hline
\end{tabular}

Table 3 reveals the behaviors related to stalking campaigns like unwanted approaches, unwanted communication, and intimidation. The results show significant results following the victims $\chi^{2}(1)=9.323, \mathrm{P}<.005$ and standing outside the house/workplace and $\chi^{2}(1)=14.750, \mathrm{P}<.005$ 
as unwanted approaches and unwanted phone calls $\chi^{2}(1)=11.107, \mathrm{P}<.005$ and stalk through social networking sites $\chi^{2}(1)=11.157, \mathrm{P}<.005$ as unwanted communications and staring $\chi^{2}(1)=61.383$, $\mathrm{P}<.005$ and threat to kill your loved one $\chi 2(1)=7.428, \mathrm{P}<.005$ as intimidation.

Table No. 4 Consequences of Stalking Campaign

\begin{tabular}{|c|c|c|c|c|c|}
\hline $\begin{array}{l}\text { Effects on } \\
\text { victims }\end{array}$ & Students & Male & Female & $x^{2}$ & $\mathrm{p}$ \\
\hline $\begin{array}{l}\text { Horrified } \\
\text { from this act }\end{array}$ & $\begin{array}{l}\text { Yes } \\
\text { No }\end{array}$ & $\begin{array}{c}0(0 \%) \\
108(35 \%)\end{array}$ & $\begin{array}{c}192(64 \%) \\
2(1 \%)\end{array}$ & 293.964 & .000 \\
\hline & Yes & $6(2 \%)$ & $146(48 \%)$ & 134.831 & .000 \\
\hline $\begin{array}{l}\text { Take off from } \\
\text { university }\end{array}$ & No & $102(33 \%)$ & $48(16 \%)$ & & \\
\hline $\begin{array}{l}\text { Take off from } \\
\text { social } \\
\text { activities }\end{array}$ & $\begin{array}{l}\text { Yes } \\
\text { No }\end{array}$ & $\begin{array}{c}5(2 \%) \\
110(36 \%)\end{array}$ & $\begin{array}{c}103(33 \%) \\
84(28 \%)\end{array}$ & 79.780 & .000 \\
\hline $\begin{array}{l}\text { Take off from } \\
\text { household } \\
\text { chores }\end{array}$ & $\begin{array}{l}\text { Yes } \\
\text { No }\end{array}$ & $\begin{array}{c}11(4 \%) \\
97(32 \%)\end{array}$ & $\begin{array}{c}145(48 \%) \\
49(16 \%)\end{array}$ & 115.782 & .000 \\
\hline $\begin{array}{l}\text { Feel } \\
\text { distressed }\end{array}$ & $\begin{array}{l}\text { Yes } \\
\text { No }\end{array}$ & $\begin{array}{l}50(17 \%) \\
58(19 \%)\end{array}$ & $\begin{array}{c}122(40 \%) \\
72(24 \%)\end{array}$ & 7.789 & .004 \\
\hline
\end{tabular}

Table 4 reveals the consequences of behaviors related to stalking campaigns. The findings show significant results horrified from this act $\chi^{2}(1)=293.964, \mathrm{P}<.005$ and $64 \%$ female students as compared to no male students reported fear from being stalked. The consequences are far-reaching on female students than male students $\chi^{2}(1)=134.83, \mathrm{P}<.005$ as $48 \%$ of female students take off from university as compared to $2 \%$ male students. While $33 \%$ female students as compared to $2 \%$ male students left from social activities because of being stalked. The chi-square value is $\chi^{2}(1)=79.780$, $\mathrm{P}<.005$. The $48 \%$ female as compared to $4 \%$ male students are unable to do household chores as a result of the stalking campaign and the chi-square value is $\chi^{2}(1)=115.782, \mathrm{P}<.005$. The $40 \%$ female as compared to $17 \%$ male students feel distressed as a result of the stalking campaign and the chisquare value is $\chi^{2}(1)=7.789, \mathrm{P}<.005$.

\section{DISCUSSION}

The study was conducted to see the prevalence of stalking and the differences of experiences between male and female students at public sector Co-education Universities of the twin cities of Rawalpindi/Islamabad. The sample was $20 \%$ of all undergraduate students of all three public sector universities of twin cities. The findings showed that $51 \%$ of students experienced stalking during university life and out of this, 33\% were female and $18 \%$ were male students. These results are consistent with the previous studies that majority of stalking victims were women (Dressing, et al., 2005; Morville, 1993; Narud, et al., 2014; Puurcellet, et al., 2002). Stalkers were male students in most of the cases and female students were the victims. The results resonate with the study of Bulut et al., (2021) that the prevalence of stalking campaigns from their clients ranges with 6-53 percentage depending upon the nature of the profession. Another study conducted by Aquadro, et al., (2020) that $68 \%$ of women and $32 \%$ of men filed stalking cases to police in Italy. The findings further confirm that stalking is an inter-gender phenomenon (Sheridan, et al., 2016), as well as females faced stalking campaigns more than males (Narud \& Dahl, 2015; Narud, et al.., 2014; Purcell, et al., 2002). Moreover, the nature of the relationship of $60 \%$ female and $19 \%$ male students was ex-friend with the offender. Several studies found that in most of the cases, the stalker and victim know each other (Aquadro \& Varetto., 2018; Dovelius, et al., 2006; Dressing, et al., 2005).

Regarding victimization between female and male students who experienced stalking campaigns, the results showed significant results of category unwanted approach of stalking behaviors of following the victims which $37 \%$ female as compared to $14 \%$ male faced this victimization from each other. Another unwanted approach is to stand outside the department, library, or cafeteria which 
is faced by $20 \%$ female and $4 \%$ male, and the third behavior of stalking campaign is staring at others where the results are significant, more female students (58\%) as compared to male (18\%) victimized by stalking behavior. The following, staring, and standing outside the departments, library, and cafeteria in the university is easy for boys and girls as stalking behaviors. These results are consistent with the previous studies where more male stalkers than female stalkers approach unwantedly to the victims (Spitzberg \& Cupach, 2014; McEwan et al., 2012). The second category of stalking behavior campaign was unwanted communications. The results were found significant unwanted phone calls where $57 \%$ female students as compared to $28 \%$ male students faced victimization of stalking, as well as $30 \%$ female students as compared to $20 \%$ male students received these unwanted text messages while $58 \%$ female students as compared to $27 \%$ male students faced victimization through social networking sites. The students' community use this category very frequently to stalk each other. These results confirm the results of previous studies of stalking communication behavior through cell phones, text messages, and using social networking sites (Spitzberg \& Cupach, 2014; McEwan et al., 2012; Rosenfeld \& Lewis, 2005; Bud et al., 2000; Westrup et al., 1999). The results of the third category intimidation as stalking behaviors through verbal abusing, threatening to kill oneself, or loved ones were found non-significant and these results are not confirming the previous literature it may be because of a cultural context where students in the public sector universities must bear the consequences so they do not use these dangerous or abusive aspects of the stalking campaigns.

The second objective of the research was to find out the effects of stalking behavior campaigns on victims. The results showed significant effects on the female students as compared to male students because of stalking behavior campaigns. One of the effects of stalking behavior is the internationalization of fear among the victims and the results showed that $64 \%$ of female students' internalized fear because of stalking behavior campaigns as compared to zero percent of male students who do not feel fear of the stalking behaviors. The results are supported by the previous literature that stalking behavior campaigns can affect the life of the victims and it may be possible to become a major reason for their fear among women (Aquadro et al., 2020; Korkodeilou 2016; Sheridan \& Lyndon, 2012). The effects of stalking behavior campaigns are more on women as $48 \%$ of female students as compared to $2 \%$ male students take off from the university as well as $33 \%$ women as compared to $2 \%$ male students leave the social activities. Furthermore, $48 \%$ of female students as compared to $04 \%$ of male students are unable to do household chores due to stalking behavior. These results are in line with the study conducted by Korkodeilou (2016) that reported that the victims faced difficulties in making their relationship with families, friends, and parents. The alienation, social isolation, and mental health problems worsen the quality of life of the victims due to the threatening nature of stalking behavior. The significant results of students feeling distressed due to stalking behavior and $40 \%$ female as compared to $17 \%$ male students reported these behaviors. The results confirm the previous studies that both males and females went into stress but mostly women as compared to men feel stressed as a consequence of the stalking behavior (Aquadro et al., 2020).

\section{CONCLUSION}

Stalking behavior is widespread among university students in Pakistan. Stalkers in most cases are male students and female students are victims, but the results also show female students as stalkers. Stalking is a nightmare for female students because they are the worst affected by this stalking behavior campaign and that changed all aspects of their life whether personal, educational, or social. They live under extreme fear of being under a watchful eye, being following in all her activities. They cut their social activities, in some cases, leave their education, and are unable to participate in household chores. They feel difficulty in building their relationships with families, friends, and parents because in most cases, the offenders are their ex-boyfriends. On the other hand, the results of male students about stalking behavior are different as male students are not in fear of stalking behavior and it did not affect their educational, social, or personal life. Male students are stalked mostly by unknown girls, though that is stressful for them but it neither creates fear among them nor does it have any effect on their life.

\section{REFERENCES}


Abrams, K., \& Robinson, G. (2011). Stalking by Patients: Doctors' Experiences in a Canadian Urban Area. The Journal of Nervous and Mental Disease. 199, 738-743. https://doi.org/10.1097/NMD.0b013e31822fc7aa

Acquadro, M., \& Varetto, A. (2018). Psychological Impact of Stalking on Male and Female Health Care Professional Victims of Stalking and Domestic Violence. Frontiers in Psychology. 9 , 321-329. http://doi.org/10.3389/fpsyg.2018.00321

Acquadro, M., Varetto, A., Corona, I., \& Tirassa, M. (2020). Characteristics of the stalking campaign: Consequences and coping strategies for men and women that report their victimization to police. PLOS ONE 15(2), 229-242. http://doi.org/10.1371/journal.pone.0229830

Bjerregaard, B. (2000). An empirical study of stalking victimization. Violence and Victims, 15(4), 389-406.

Budd, K., Mattinson, K., \& Myhill, M. (2000). Extent and Nature of Stalking: Findings from the 1998 British Crime Survey. Home Office

Bulut, S., Usman, A., \& Nazir, T. (2021) Stalking of Healthcare Professionals by Their Clients: The Prevalence, Motivation, and Effect. Open Journal of Medical Psychology. 10, 27-35. https://doi.org/10.4236/ojmp.2021.102003

Dovelius, A., Öberg, J., \& Holmberg, S. (2006). Stalking in Sweden: Prevalence and Prevention. Stockholm: National Council.

Dressing, H., Kuehner, C., \& Gass, P. (2005). Lifetime prevalence and impact of stalking in a European population: Epidemiological data from a middle-sized German city. British Journal of Psychiatry. 187, 168-172.

Fox, K., Nobles, M., \& Akers, R. (2011). Is stalking a learned phenomenon? An empirical test of social learning theory. Journal of Criminal Justice, 39(1), 3947. https://doi.org/10.1016/j.jcrimjus.2010.10.002

Hall, D. (1998). The victims of stalking. In. Meloy J. (ed.). The psychology of stalking: Clinical and forensic perspectives. San Diego, CA: Academic Press.

Korkodeilou, J. (2016). Stalking Victims, Victims of Sexual Violence and Criminal Justice System Responses: Is there a Difference or just 'Business as Usual'? The British Journal of Criminology, 56(2), 256-273. https://doi.org/10.1093/bjc/azv054

McEwan, T., MacKenzie, R., Mullen, P., \& James, D. (2012). Approach and escalation in stalking. Journal of Forensic Psychiatry \& Psychology. 23(3), 392-409.

Mullen, P., Pathé, M., \& Purcell, R. (2000). Stalkers and their victims. Cambridge University Press, Cambridge.

Narud, K., \& Dahl, A. (2015) Stalking experiences reported by Norwegian members of Parliament compared to a population sample, The Journal of Forensic Psychiatry \& Psychology. 26(1), 116-131. http://doi.org/10.1080/14789949.2014.981564

Purcell, R., Pathe, M., \& Mullen, P. E. (2005). Association between Stalking Victimisation and Psychiatric Morbidity in a Random Community Sample. The British Journal of Psychiatry. 187, 416-420. https://doi.org/10.1192/bjp.187.5.416 .......................... (2002). The Prevalence and Nature of Stalking in the Australian Community. Australian \& New Zealand Journal of Psychiatry, 36(1), 114 120. https://doi.org/10.1046/j.1440-1614.2002.00985.x

Rosenfeld, B., \& Lewis, C. (2005). Assessing Violence Risk in Stalking Cases: A Regression Tree Approach. Law and Human Behavior, 29(3), 343-357. https://doi.org/10.1007/s10979-0053318-6

Sheridan, L., \& Lyndon, A. (2012). The influence of prior relationship, gender, and fear on the consequences of stalking victimization. Sex Roles. 66(5-6), 340-50.

Spitzberg, B., Cupach, W., \& Ciceraro, L. (2010). Sex differences in stalking and obsessive relational intrusion: Two meta-analyses. Partner Abuse. 1(3), 259-285.

Spitzberg, B., \& Cupach, W. (2014). The dark side of relationship pursuit: From attraction to obsession and stalking. Routledge

Tjaden, P., \& Thoennes, N. (2000). Prevalence and consequences of male-to-female and female-tomale intimate partner violence as measured by the National Violence Against Women Survey. Violence against women, 6(2), 142-161. 
Van der Aa, S. (2018). New trends in the criminalization of stalking in the EU member states.

European Journal on Criminal Policy Research, 24, 315-333. https://doi.org/10.1007/s10610017-9359-9

Walby, S., \& Allen, J. (2004). Domestic violence, sexual assault and stalking: Findings from the British Crime Survey. London: Home Office.

Westrup, D., \& Fremouw, W. (1998). Stalking behavior: A literature review and suggested functional analytic assessment technology. Aggression and Violent Behavior. 3(3), 255-274. 